\title{
Performance Assessment Modeling for Savannah River Glass HLW Disposal in a Potential Repository at Yucca Mountain
}

\author{
W.J. O'Connell \\ W.L. Bourcier \\ J. Gansemer \\ T.S. Ueng
}

This paper was prepared for submittal to the

American Chemical Society National Meeting/Symposium on Science and Technology for Disposal of Radioactive Tank Wastes

Las Vegas, $N V$

September 8-11, 1997

August 1997

This is a preprint of a paper intended for publication in a journal or proceedings. Since changes may be made before publication, this preprint is made available with the understanding that it will not be cited or reproduced without the permission of the author. 


\section{DISCLAIMER}

This document was prepared as an account of work sponsored by an agency of the United States Government. Neither the United States Government nor the University of California nor any of their employees, makes any warranty, express or implied, or assumes any legal liability or responsibility for the accuracy, completeness, or usefulness of any information, apparatus, product, or process

disclosed, or represents that its use would not infringe privately owned rights. Reference herein to any specific commercial product, process, or service by trade name, trademark, manufacturer, or otherwise, does not necessarily constitute or imply its endorsement, recommendation, or favoring by the United States Government or the University of California. The views and opinions of authors expressed herein do not necessarily state or reflect those of the United States Government or the University of California, and shall not be used for advertising or product endorsement purposes. 


\title{
PERFORMANCE ASSESSMENT MODELING FOR SAVANNAH RIVER GLASS HLW DISPOSAL IN A POTENTIAL REPOSITORY AT YUCCA MOUNTAIN *
}

\author{
W.J. O'Connell, W.L. Bourcier, J. Gansemer, and T.-S. Ueng ${ }^{1}$ \\ Lawrence Livermore National Laboratory \\ Livermore CA 94550 \\ ${ }^{1}$ Present address: Civil Engineering Dept., National Taiwan University, Taipei, \\ Taiwan.
}

\section{INTRODUCTION}

Performance assessment (PA) simulates the long-term performance of a conceptual geological repository for nuclear waste or the performance of a subsystem such as the engineered barrier system (drifts, waste packages, and any components placed in the drift for structural or chemical purposes). The analysis must accommodate many hypothetical future scenarios and a range of input parameter values. Hence the PA models must abstract the major process features, to span the range of evaluations with computational efficiency and to allow for sensitivity evaluations of the total system. This abstraction is guided by experiments and detailed calculational evaluations for specific situations. The present paper shows the setting of a glass-waste chemical alteration model within the larger-scope PA model, a typical abstraction for a glass aqueous alteration model, and thus the types of topics we need to cover as exemplified by the model. The abstraction includes the most important constituents of the water contacting the waste, and an effect on the rate from the increasing silica going into solution. The interfaces to other processes at the boundary of this process domain identify some important issues.

The present example focuses on SRL-202 glass, but other glass types could be handled by a similar experiment-review and model abstraction process, in some cases resulting in a similar model with different parameters.

\section{CONTEXT}

Figure 1 shows, on the left, the outline of a PA model's scope. External scenarios such as a varying climate and features such as the rate of fracture-matrix interaction in groundwater

\footnotetext{
* Work performed under the auspices of the U. S. Department of Energy by Lawrence Livermore National Laboratory under Contract W-7405-Eng-48.
} 
flow provide the setting. Then flow and geochemical processes, and eventual corrosion of waste packages, establish the glass waste's immediate environment. The range of scenarios and the localized details of groundwater contact with engineered materials lead to a range of environments for the glass waste. The waste form model tracks the alteration of the waste form and the mobilization of radioactive elements as solutes or colloids for transport. Figure 1 shows, on the right, the outline of the glass waste form model at a finer level of detail. Vapor phase hydration can alter some of the monolithic glass waste form, if the container has been breached, even before liquid water reaches the glass. Water contact can alter the glass and provide a medium for transport of some of the waste. Solubility limits and colloid formation have an effect on how much waste can be transported away from the waste package.

This paper shows how experimental information on aqueous alteration can be summarized in a form useful in a performance assessment model. Parameter links to neighboring vapor-phase and solubility models can be provided by the device of storage compartments of modified materials.

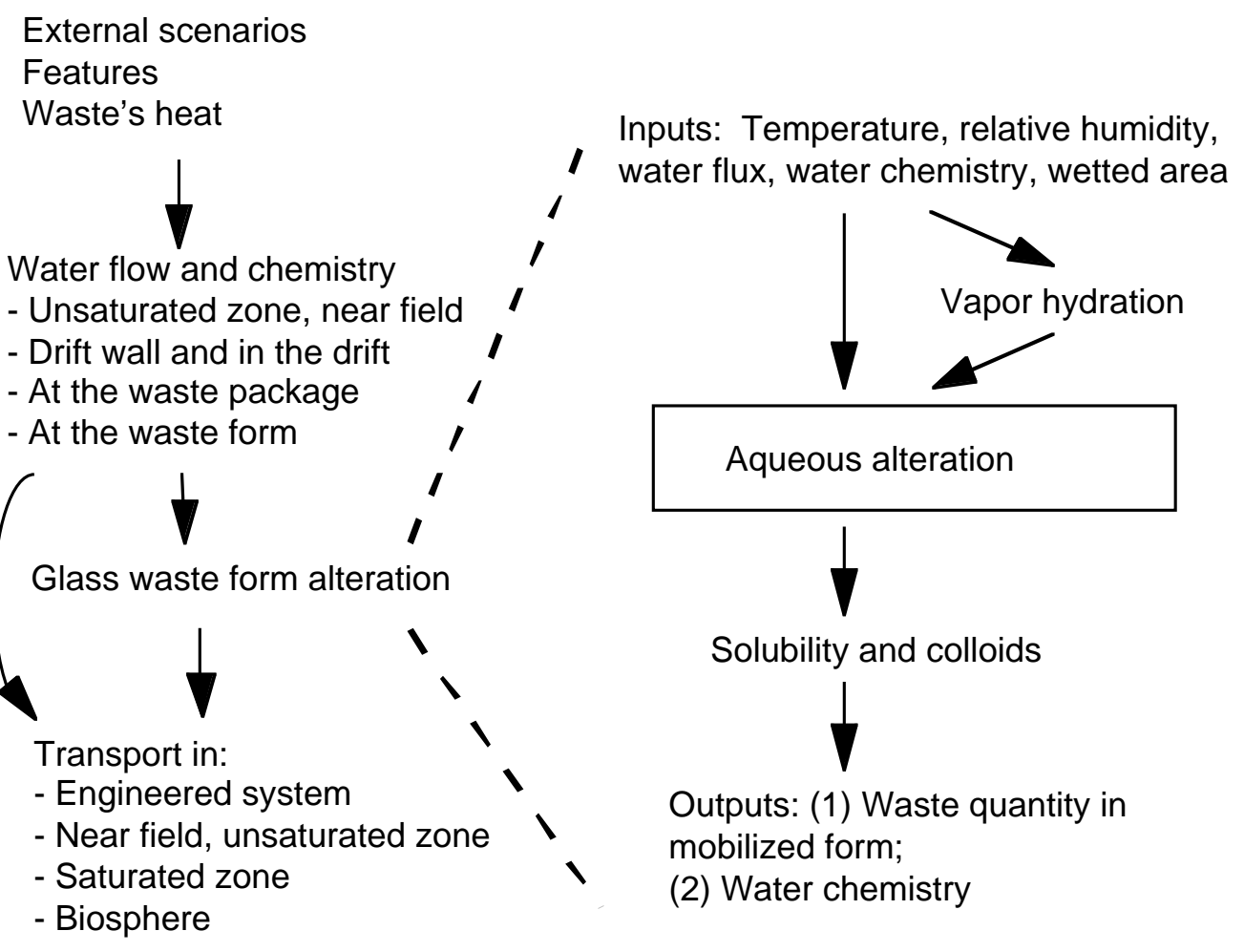

Figure 1. Outline of the performance assessment model's scope (left) and glass waste form alteration model (right). The present paper focuses on the submodel for aqueous alteration of the glass (rectangle). The products from vapor hydration are an input condition for this submodel, and the silica and other constituents exposed by glass alteration are among the inputs to a solubility model, which provides another possible constraint on the amount of waste available for transport.

\section{GLASS ALTERATION RATE}

Experimental and modeling work on aqueous alteration of borosilicate glass shows that the important parameters which need to be considered in order to predict radionuclide release rates from the glass block are temperature, exposed surface area, solution $\mathrm{pH}$, and dissolved 
silica concentration in solution. Currently, the most successful long-term dissolution models for borosilicate glass employ a rate equation consistent with transition state theory. A simplified rate equation can be given as: ${ }^{1}$

$$
\mathrm{R}=\operatorname{sk}\left[1-\left(\frac{\mathrm{Q}}{\mathrm{K}}\right)^{\sigma}\right]
$$

where $R$ = alteration rate of glass $(\mathrm{g} / \mathrm{yr})$,

$s=$ surface area $\left(\mathrm{m}^{2}\right)$,

$k=$ glass surface alteration rate constant $\left(\mathrm{g} / \mathrm{m}^{2} / \mathrm{yr}\right)$,

$=\mathrm{a}$ function of temperature and $\mathrm{pH}$ of the solution,

$Q=$ concentration of dissolved silica $\left(\mathrm{g} / \mathrm{m}^{3}\right.$ water $)$,

$K=$ a quasi-thermodynamic parameter for borosilicate glass,

$\approx$ solubility of amorphous silica $\left(\mathrm{g} / \mathrm{m}^{3}\right.$ water $)$,

$\sigma=$ constant to be determined based on experimental data.

At present, the value of $\sigma$ is not well determined based on the available data. A simple and acceptable value of 1.0 is used in our model. The values for other parameters are discussed below.

Most of the experiments supporting this model and its parameter variations are either batch experiments with a fixed quantity of water, or flow-through experiments at a high flow rate. Some scenarios for water contact with a waste package involve flowing water at a low flow rate. One goal of this paper is to adapt the experimental observations in extended-time batch experiments, especially at low ratios of water volume to surface area, to the low-flow scenarios, where the ratio of water volumetric flux to wetted surface area will be important.

Equation (1) indicates that the dissolution rate will slow down as the dissolution adds to the silica $\left(\mathrm{SiO}_{2}\right)$ in solution. DWPF glass, as an example, contains about $50 \mathrm{wt} \%$ of silica. ${ }^{2}$ As the glass dissolves, secondary phases begin to precipitate. A fraction $f_{p}$ of the silica contained in the glass will be trapped in the secondary phases. Thus, only $\left(1-f_{p}\right)$ of silica in altered glass actually dissolves in the solution. The value of $f_{p}$ increases with increasing surface area to volume ratio and silica concentration in solution. Since there is not sufficient data for consideration of the change of $f_{p}$, a constant intermediate value of $f_{p}=0.5$ is assumed in our model.

Further, the experimental data for several glass compositions show that even when the solution is saturated with silica after a long period of time, there is still a long-term dissolution rate, as evidenced by the increasing concentration of certain highly soluble elements of the glass composition. We are more interested in the release of soluble radioactive elements from the glass matrix than in the silica itself, so we include this long-term glass alteration rate in our model.

\section{Rate Constant, $k$}

The rate constant, $k$, has been measured over a range of $\mathrm{pH}$ and temperature conditions. Figure 2 shows the results for $k$ in units of $\mathrm{g} / \mathrm{m}^{2} /$ day from flow-through experiments by Knauss et al. ${ }^{3}$ Regression relations for $\log _{10} k$ are also given in the figure.

\section{Solution Chemistry, $Q_{\text {Inflow }}$ and $K$}

Other than $\mathrm{pH}$, the major groundwater chemistry parameter affecting the glass dissolution rate is the concentration of dissolved silica, $Q$. The local groundwater chemistry in the vicinity of the repository will likely be dominated by the host rocks ${ }^{4}$ and the incoming 
silica concentration $Q_{\text {Inflow }}$ is therefore expected to be close to cristobalite saturation at the ambient temperature. Cristobalite is a common constituent of the host rocks at Yucca Mountain. Table 1 lists concentrations of silica in equilibrium with cristobalite at temperatures from 0 to $150^{\circ} \mathrm{C}$ from the thermodynamic database SUPCRT92. ${ }^{5} \mathrm{~K}$ in Equation (1) for the waste glass in this simple model is assumed equal to the equilibrium constant for amorphous silica. $K$ actually varies as a function of glass composition, but for most waste glass compositions, the experimentally determined value of $K$ is of the same general magnitude but less than the value of $K$ for amorphous silica. Our simplification therefore gives conservative estimates. Table 1 also lists values of $\log _{10} K$ (in molality) for temperatures from 0 to $150^{\circ} \mathrm{C}$. For temperatures between 0 and $100^{\circ} \mathrm{C}$, the relations can be expressed, with $T$ in ${ }^{\circ} \mathrm{C}$ and $K$ in $\mathrm{g} / \mathrm{m}^{3}$, as:

$$
\begin{aligned}
& Q_{\text {Inflow }} / K=0.128+0.0021 T \\
& K=60 .+1.90 T+1.25 \times 10^{-2} T^{2}
\end{aligned}
$$

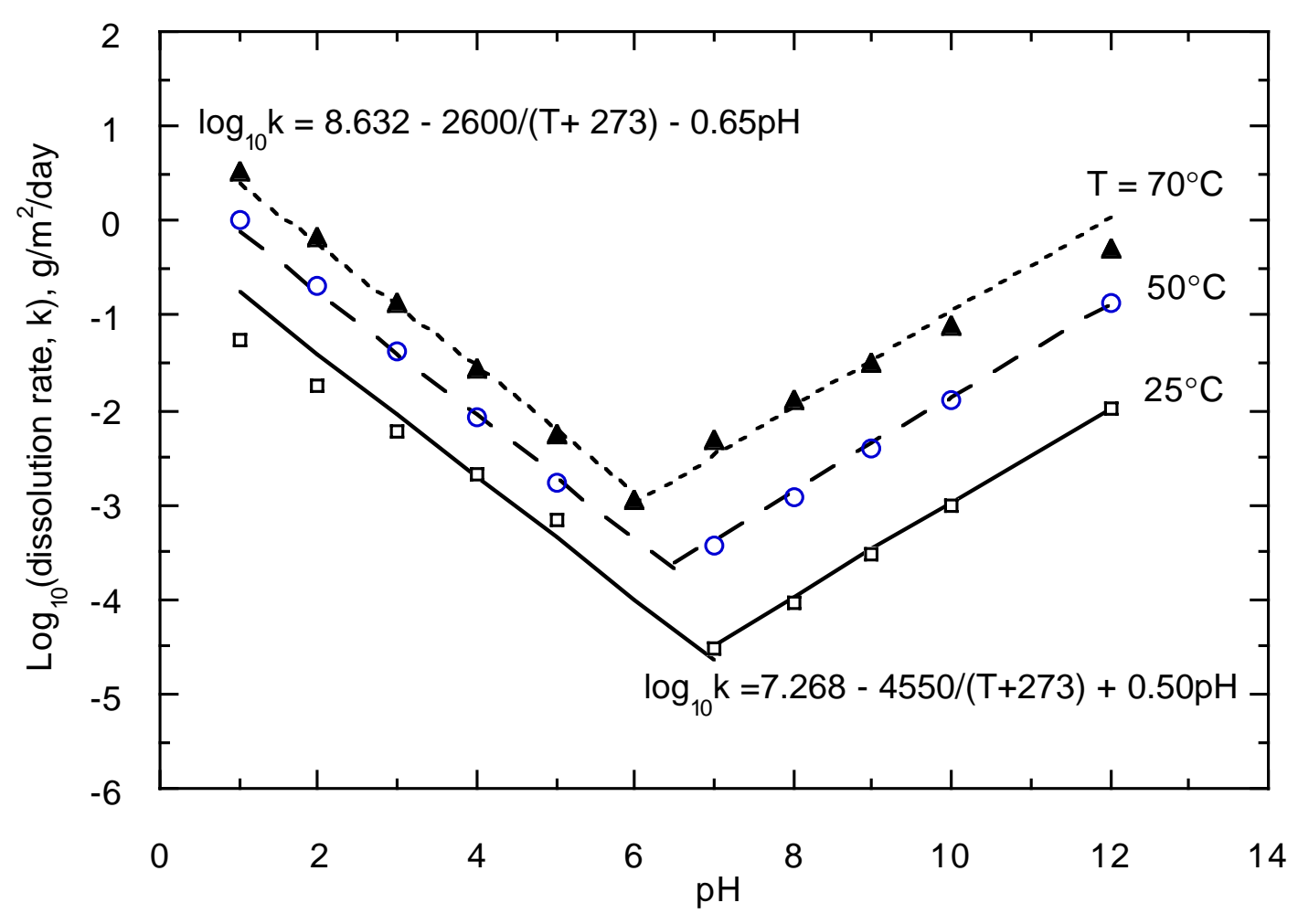

Figure 2. $\log _{10}$ (dissolution rate $k, \mathrm{~g} / \mathrm{m}^{2} /$ day) versus solution $\mathrm{pH}$.

Table 1. Cristobalite and amorphous silica solubilities [tabulating $\log _{10}$ (molality)]

\begin{tabular}{|c|c|c|c|c|c|c|}
\hline Temperature, ${ }^{\circ} \mathrm{C}$ & 0 & 25 & 60 & 90 & 100 & 150 \\
\hline Cristobalite, $=Q_{\text {Inflow }}$ & -3.89 & -3.45 & -3.02 & -2.75 & -2.68 & -2.36 \\
\hline Amorphous Silica, $=K$ & -2.99 & -2.71 & -2.43 & -2.26 & -2.20 & -1.98 \\
\hline
\end{tabular}




\section{Long-term Dissolution Rate}

As mentioned above, even when the solution is saturated with silica after a long period of time, there is still a non-zero dissolution rate. Because we currently do not have a mechanistic model that can predict the variation of the long-term rates with environmental parameters, an averaged value of $k_{\text {long }}=0.002 \mathrm{~g}$ glass $/ \mathrm{m}^{2} /$ day is recommended for SRL-202 glass. This value was obtained from glass corrosion tests at $90^{\circ} \mathrm{C}$. For other temperatures, the same temperature dependency relation for $k$ is assumed as in Fig. 2. That is, for $\mathrm{pH} \geq 7$,

$$
\mathrm{k}_{\text {long }} \approx 10^{\delta} \mathrm{g} / \mathrm{m}^{2} / \mathrm{yr} \quad \text { with } \delta=12.40-\frac{4550}{\mathrm{~T}+273}
$$

Then the alteration rate $R$ in place of Equation (1) is

$$
\mathrm{R}=\mathrm{sk}_{\mathrm{long}}
$$

This simple model ignores all solution chemistry other than $\mathrm{pH}$ and silica concentration. We know from a variety of experiments that species such as dissolved $\mathrm{Mg}$ and Fe can change glass dissolution rates by up to several orders of magnitude. Mg decreases the rate, Fe increases the rate. We do not account for effects such as these in this model. We also leave vapor phase alteration of the glass for a separate but connected model; see qualitative discussion later in this paper.

\section{GLASS RELEASES FROM A WASTE PACKAGE}

Two water contact modes, flow-through and pool modes, are considered here and shown schematically in Fig. 3. In the flow-though mode, we assume the water flows down the side of a waste glass log and keeps a surface area, $s$, wet. As any unit volume of water flows downward, it dissolves some glass and increases its silica concentration until it departs at the bottom. We assume there is no mixing of a moving unit volume with adjacent volumes before or behind it in the flow path. The pool mode has thorough mixing of the water, providing a spatially constant silica concentration. In a steady state, the silica going into solution from the glass per year is balanced by the silica carried away, which equals the flux times the outgoing minus incoming concentrations. A pool could be a small puddle fed by a drip or it could fill a waste package with a breach near the top as illustrated in the figure. During the filling transient the wetted area increases, so the silica concentration only gradually approaches a steady-state value.

In a moving mass of water in the flow-through contact mode, the dissolution rate will slow down as the silica in solution increases, as discussed above with Equation (1). The mass fraction of silica in the glass composition, $f_{s i}$, and the fraction of dissolving silica which becomes trapped in secondary phases, $f_{p}$, play a part in this evolving balance.

In the same evolving solute chemistry, the $\mathrm{pH}$ will change and hence will also affect the dissolution rate. However, the change in $\mathrm{pH}$ will be a complex function of the flow rate, buffer capacity of the fluid, and alkali content of the glass. There is insufficient data to obtain a relationship for the change of $\mathrm{pH}$ due to the dissolution of glass. Therefore, a constant $\mathrm{pH}$ value of the flowing water is used in the calculations below. For the flow-through mode with a high flow rate, the $\mathrm{pH}$ value of the inflowing groundwater is appropriate. For a low flow rate with extensive alteration, the $\mathrm{pH}$ trends to higher values; the higher value should be used as the constant value. 


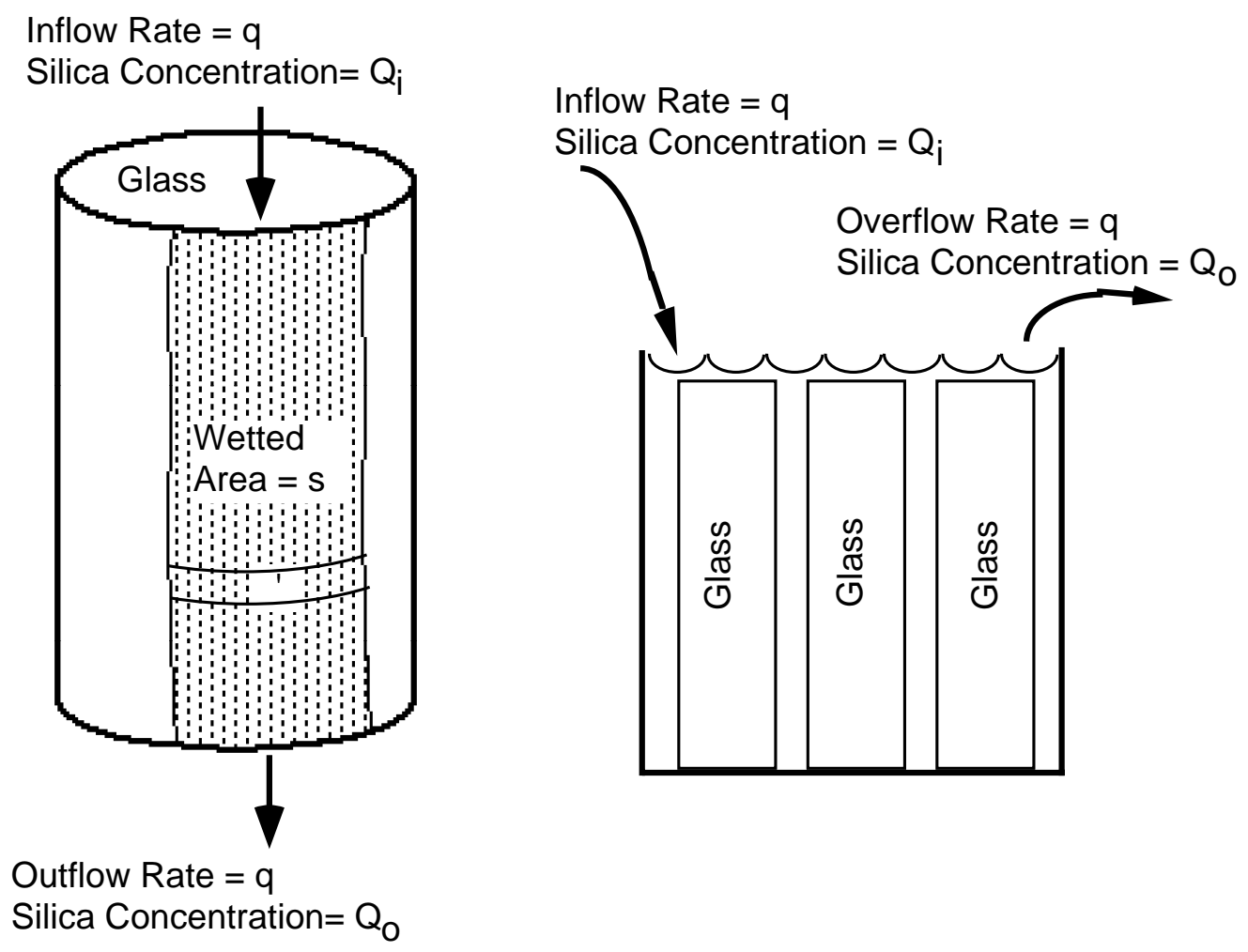

Figure 3. Flow-through (with no mixing) and pool (with full mixing) water contact modes.

\section{Surface Area}

After being poured and cooled, the glass undergoes fracturing. Estimates for the increase in glass surface area due to fracturing range from 2 to 100 times the uncracked surface area. A reasonably conservative value to use is $25{ }^{6}$ The initial total glass surface area per waste package, $A_{o}$, is made up of a nominal area per glass log, number of glass logs per package, $n$, and a cracking factor $F$, a multiplier on the nominal area. The total surface area is typically on the order of $300 \mathrm{~m}^{2}$, assuming $n=4$ and $F=25$. For low water flux we expect a rather limited area can be wetted. The wetted area, $s$, generally depends on the groundwater flow rate, $q$, and is an input in our model. To complete the model we make the strawman assumptions (i) the wetted area stays at a constant size as long as it is less than the total surface area, and (ii) the total surface area decreases as the remaining unaltered mass decreases. Some further discussion is given below when we consider vapor hydration.

\section{Flow-through Mode}

The area of the glass log wetted by water, $s$, is to be determined within the model for in-package hydrology. A larger wetted area produces a larger release. But the silica in solution effect moderates the increase with area, for a fixed water flux.

With a thickness of the water film on the glass of $\Delta$, the volume of water covering the glass is $(s \Delta)$. (Fortunately $\Delta$ will cancel out in the following development.) When groundwater of a flow rate of $q$ covers a portion of surface area as shown in Fig. 3, the time for the water to flow in and out of the package is 


$$
t_{\text {out }}=s \Delta / q \text {. }
$$

As the water proceeds downward, the silica increases and the reaction rate slows down. For a steady state flow condition, the glass dissolution condition can be considered by following a moving unit volume of water $\left(s^{\prime} \Delta\right)$ contacting the glass for a duration of $t_{\text {out }}$. We let $u=t / t_{\text {out }}$. The increase of silica concentration during a scaled-time interval, $\mathrm{d} u$, is:

$$
\mathrm{d} Q=(f s k / q)(1-Q / K) \mathrm{d} u
$$

$$
\begin{aligned}
& \text { where } \quad f=f_{s i}\left(1-f_{p}\right) \\
& f_{s i}=\text { fraction of silica in glass } \\
& f_{p}=\text { fraction of altered silica trapped in secondary phases }
\end{aligned}
$$

This equation could be integrated by a finite difference method while $k$ and $K$ vary with temperature. But we assume that $t_{\text {out }}$ is small enough that the temperature does not change significantly during the movement of a small unit mass through the glass-water system. Then we can integrate analytically. If the silica concentration of incoming groundwater is $Q_{i}$, and that of outgoing is $Q_{O}$ after a duration of $t_{\text {out }}$, then

$$
\mathrm{Q}_{\mathrm{O}}-\mathrm{Q}_{\mathrm{i}}=\mathrm{K}\left(1-\frac{\mathrm{Q}_{\mathrm{i}}}{\mathrm{K}}\right)[1-\exp (-\alpha)]
$$

where $\alpha=\frac{f k s}{K q}$.

For intermediate points along the flow, we rewrite (7) to

$$
\mathrm{Q}(\mathrm{x})-\mathrm{Q}_{\mathrm{i}}=\mathrm{K}\left(1-\frac{\mathrm{Q}_{\mathrm{i}}}{\mathrm{K}}\right)\left[1-\exp \left(-\alpha \bullet \mathrm{x} / \mathrm{x}_{\max }\right)\right]
$$

For large $q$ compared to $(f k s)$, we have a "high-flow" condition dominated by the incoming water. Then using the approximation $\exp (-\alpha)=1-\alpha$, Equation (7) can be changed to a form similar to Equation (1).

For small $q$ compared to $(f k s)$, the system is dominated by the glass surface reaction and approaches a silica-saturated condition. Also $f_{p}$ starts changing toward high values but there is not very precise data for $f_{p}$. We use the constant intermediate value of 0.5 . Applying the small- $q$, high- $\alpha$ case to Equations (7) and (8), $\exp (-\alpha)$ approaches zero, and $\exp (-$ $\left.\alpha \bullet x / \mathrm{x}_{\max }\right)$ approaches zero as $\alpha$ and/or $x$ increase. Then $Q(x)$ approaches a limit $K$ and $\mathrm{d} Q$ in Equation (6) approaches zero.

The silica transported away per $\mathrm{m}^{3}$ of water is $\left(Q_{O}-Q_{i}\right)$. The corresponding amount of glass altered (in grams) is higher. Then $R$, the dissolution rate $(\mathrm{g} / \mathrm{yr})$ from the whole waste glass in the waste package is:

$$
R=\frac{q}{f}\left(Q_{o}-Q_{i}\right)
$$

and the release rate of soluble radionuclides is proportional to this $R$.

Rate control by long-term rate. When the incoming silica concentration is very near its effective saturation limit $K$, then a long-term rate applies for the entire wetted surface. 
Then the alteration rate $R$ is given by Equation (5).

Transition in rate-controlling mechanism. For some cases there is a transition of the dissolution rate controlling mechanism from Equation (1) to Equation (5) at an intermediate point before a mass of water exits from the glass surface. The transition occurs at a point $\tau=$ $t / t_{\text {out }}=x / x_{\max }$ defined by the equality of localized rates:

$$
\mathrm{k}_{\text {long }}=\mathrm{k}\left(1-\frac{\mathrm{Q}(\tau)}{\mathrm{K}}\right)=\mathrm{k}\left(1-\frac{\mathrm{Q}_{\mathrm{i}}}{\mathrm{K}}\right) \exp (-\alpha \tau)
$$

\section{Pool Mode}

A simple steady-state limit can be found for the completely mixed water reservoir case, and assuming constant temperature, by equating the silica moving out, $q \cdot\left(Q_{O}-Q_{i}\right)$, with the silica going into solution, $f_{s} \boldsymbol{k} \bullet\left(1-Q_{O} / K\right)$.

Then $\left(Q_{O}-Q_{i}\right)=\alpha\left(K-Q_{O}\right)$, where $\alpha$ is the same as in the flow-through mode. Rearranging,

$$
\left(Q_{O}-Q_{i}\right)=\left(K-Q_{i}\right) \cdot \frac{\alpha}{\alpha+1}
$$

This is similar in form to Equation (7), except for $\alpha /(\alpha+1)$ in place of $[1-\exp (-\alpha)]$. For any given $\alpha$, the net outflow rate $q \bullet\left(Q_{O}-Q_{i}\right)$ of silica, proportional to the mass dissolution rate and to the rate of releasing radionuclides from the glass block, is higher for the flowthrough mode of Equation (7) than the pool mode of Equation (11).

During filling of the container, or during buildup of a puddle on a flat glass surface, the wetted surface area increases gradually to its steady-state area. Then the silica and radionuclides in solution are less than in the steady-state balance just given, and increase toward the balance as a limit. Equations for this transient period are available in closed form for constant-temperature conditions, ${ }^{7}$ and can be determined by finite-difference computational method for changing temperature conditions. After first filling is completed, the rate of approach toward the limit is controlled by the turnover time of the pool, which is also the fill time, $q / V_{\text {liquid }}\left(\mathrm{m}^{3} / \mathrm{y}\right.$ divided by $\left.\mathrm{m}^{3}\right)$.

\section{Vapor Hydration and Its Coupled Effects}

If a container is breached and humid air reaches the glass, the glass will react and form an alteration rind composed of hydrated glass and secondary phases. The durability of this material with respect to later contact with liquid water may be much greater or much less than the unaltered glass. The vapor alteration rate is dependent on temperature and relative humidity. A thick alteration rind may develop before liquid reaches the area to be wetted. As a simple model coupling, the vapor-altered chemical masses can be considered to be in a vapor-altered mass compartment. Upon wetting, the silica mass in the compartment, a fraction of which may be readily soluble, will increase the silica in solution and reduce the aqueous alteration rate until enough silica is carried away. The altered radionuclide masses in the compartment may be treated as exposed to the water and constrained only by solubility limits.

While some surface is wet, the remaining surface is still exposed to vapor alteration, although at a declining rate, since the temperature declines over time. Some of the remaining surface eventually comes under the "wet" regime, either as glass mass is altered by the 
aqueous process, or conceivably by a meandering water flow. A geometric formula based on mass consumption or some other formula may be postulated for the gradual transfer of dry hydrated surface area to the wet compartment.

\section{AQUEOUS ALTERATION CALCULATIONS}

We consider typical glass waste logs, four to a container, with properties listed in Table 2. We consider "ball-park" to moderately conservative glass environment conditions, as follows. The temperature at the waste packages is higher in early years, and declines below $100^{\circ} \mathrm{C}$ after some thousands of years, and declines to about $30^{\circ} \mathrm{C}$ after tens of thousands of years. The general water infiltration flux through the rock, before temporal modifications by the heat load emplaced in the repository, is anticipated to be on the order of 1 to $10 \mathrm{~mm} / \mathrm{m}^{2}-\mathrm{y}$. The cross sectional area of the glass logs in one horizontal waste package is about $2.6 \mathrm{~m}^{2}$. We consider a water flux $q$ through the package of $2.5 \times 10^{-3} \mathrm{~m}^{3} / \mathrm{y}$ as a reference case. For surface $s$ that can be wetted by this flow, we consider a ratio $q / s$ of $10^{-4}$ to $10^{-2}(\mathrm{~m} / \mathrm{y})$. This corresponds to wetted areas of 25 to $0.25 \mathrm{~m}^{2}$. We consider an incoming water chemistry controlled by contact with the host rock, ${ }^{8}$ i.e., with a silica concentration given by Table 1. The $\mathrm{pH}$ is initially 7 to 8 but increases during contact with the glass. For the calculation we use a constant $\mathrm{pH}$ of 9 .

Table 2. Input parameters used for HLW glass calculations.
Initial glass density, $\rho_{o}=2.7 \mathrm{~g} / \mathrm{cm}^{3}$,
Initial radius of glass logs, $r_{o}=0.3 \mathrm{~m}$,
Initial length of glass logs, $L_{o}=2.2 \mathrm{~m}$,
Number of logs per package, $n=4$,
Mass fraction of silica in glass, $f_{s i}=0.45$,
Fraction of altered silica in precipitates and gel layer, $f_{p}=0.5$

Figure 4, left, shows the aqueous alteration rate of the glass waste form for wetted areas $s$ of $0.25 \mathrm{~m}^{2}$ and $25 \mathrm{~m}^{2}$, with $q=2.5 \times 10^{-3} \mathrm{~m}^{3} / \mathrm{y}$, as a function of temperature. For $s=0.25$ $\mathrm{m}^{2}$, the basic rate increase with temperature slows down because of increasing silica. For $s=25$ $\mathrm{m}^{2}$, the same slowdown is seen at first, but at higher temperatures the long-term rate, which also increases with temperature, controls. Figure 4, right, shows the increase with wetted area for a fixed influx. At first the increased net rate with area is slowing down because of silica, but at higher areas the long-term rate takes over.

These examples are for incoming water chemistry dominated by the host rock. In an alternate scenario, the incoming water could be dominated by contact with concrete in the engineered system. Then the initial $\mathrm{pH}$ would be quite high, and thus the initial glass reaction rate would be quite high. Then the glass reaction products would moderate the initial rate. Because of the declining $\mathrm{pH}$, it would not be conservative to assume that the final $\mathrm{pH}$ is present for the entire water contact, and a changing $\mathrm{pH}$ could be added to the model. 


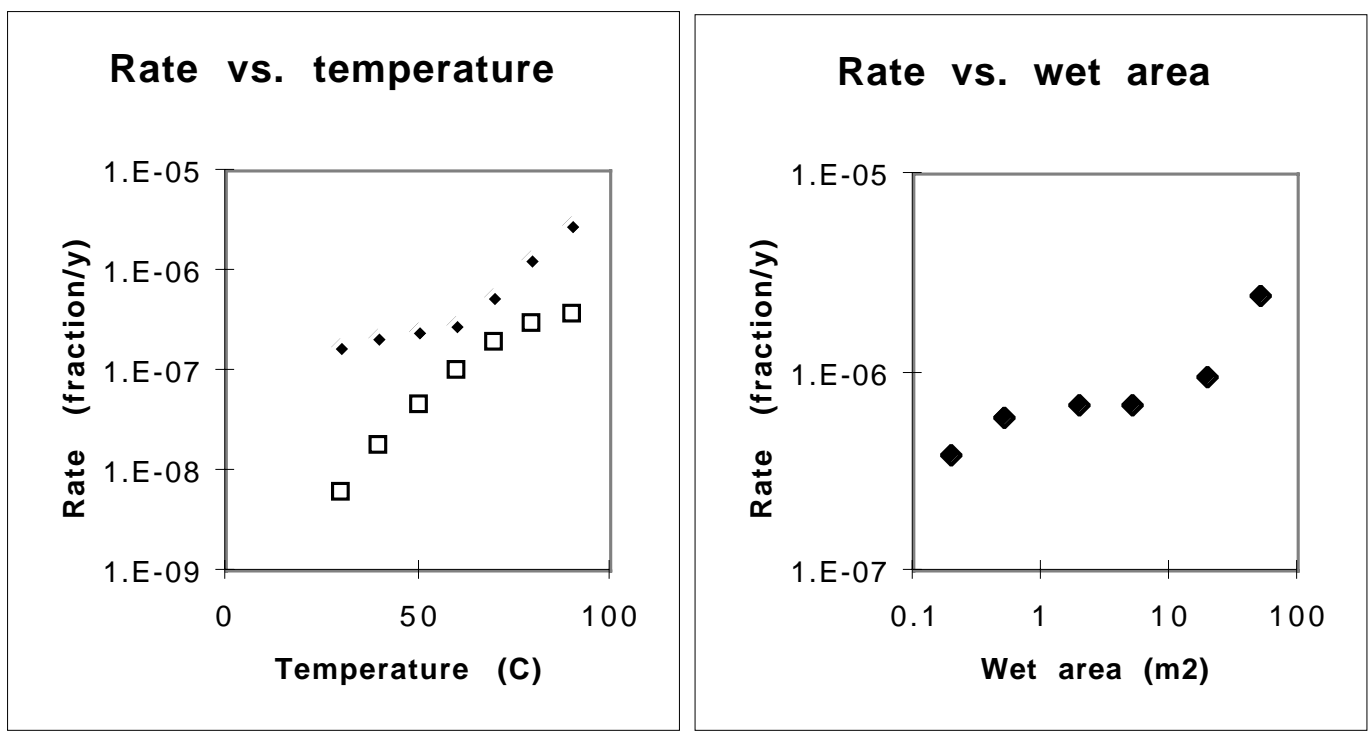

Figure 4. (Left) Aqueous alteration rate from waste package of HLW glass, varying temperature. $q=0.0025 \mathrm{~m}^{3} / \mathrm{y}$. Solid points: area $s=25 \mathrm{~m}^{2}$; open squares: $s=0.25 \mathrm{~m}^{2}$. (Right) Aqueous alteration rate, varying wetted area. $q=0.005 \mathrm{~m}^{3} / \mathrm{y}, T=80^{\circ} \mathrm{C}$.

\section{CONCLUSIONS}

Information of the aqueous alteration rate was abstracted for use in a performance assessment model. Net dissolution rate depends on the incoming water and glass chemistry and on the ratio of water flow to reaction rate. With some assumptions and approximations the model has an algebraic form and is useful for approximate sensitivity studies over a broad range of input environment values. Some simple approximate methods are suggested for connecting the aqueous alteration process model to neighboring processes which must be included in the total system performance assessment model.

\section{REFERENCES}

1. W.L. Bourcier, "Critical Review of Glass Performance Modeling," ANL-94/17, Argonne National Laboratory, Argonne, IL (1994).

2. U.S. Department of Energy, "High-Level Waste Borosilicate Glass, A Compendium of Corrosion Characteristics," DOE-EM-0177, USDOE Office of Waste Management (March 1994).

3. K.G. Knauss, et al., "Dissolution kinetics of a simple analogue nuclear waste glass as a function of $\mathrm{pH}$, time and temperature," Material Research Society Symposium Proceedings 176:371 (1990).

4. D.G. Wilder, "Near-field environment report volume I: Technical basis for EBS Design," UCRL-LR-107476, Lawrence Livermore National Laboratory, Livermore, CA (1992).

5. J.W. Johnson, E.H. Oelkers, and H.C. Helgeson, "SUPCRT92: A software package for calculating the standard molal thermodynamic properties of minerals, gases, aqueous species, and reactions from 1 to 5000 bar and 0 to $1000^{\circ} \mathrm{C}$," Computers and Geosciences 18:899 (1992).

6. R.G. Baxter, "Description of Defense Waste Processing Facility Reference Waste Form and Canister," Report DP-1606, Savannah River Plant (1983).

7. R.B. Stout et al., "Waste Forms Characteristics Report," Lawrence Livermore National Laboratory, Livermore, CA (1996).

8. K.G. Knauss, W.J. Beiriger, and D.W. Peifer, "Hydrothermal interaction of solid wafers of Topopah Spring Tuff with J-13 water at 90 and $150 \mathrm{C}$ using Dickson-type, gold-bag rocking autoclaves: Long-term experiments," UCRL-53722, Lawrence Livermore National Laboratory, Livermore, CA (1987). 


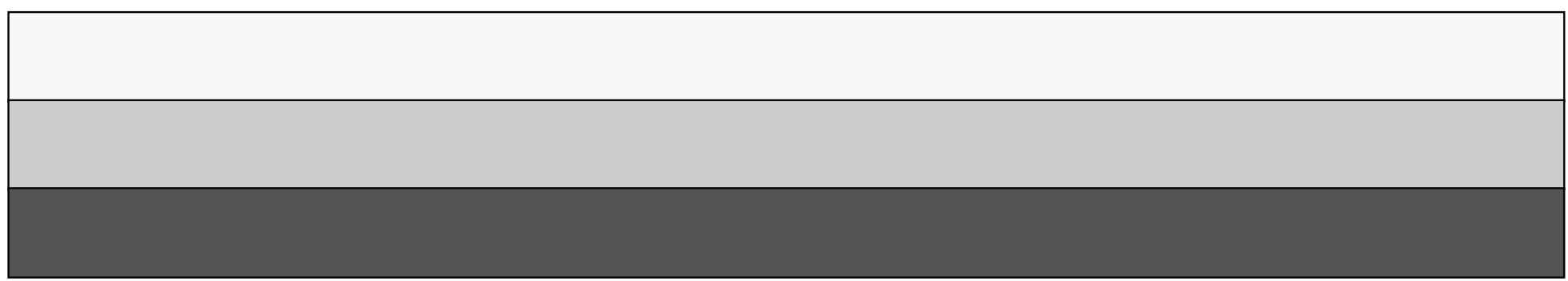

